\author{
Método Sherezade. La fotografía como
} autoconocimiento y método de aprendizaje

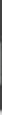

\author{
María Isabel Soler Ruiz
}

Artigo recebido em: 23/11/2020

Artigo aprovado em: 20/12/2020 


\title{
Método Sherezade. La fotografía como autoconocimiento y método de aprendizaje
}

\section{The Sherezade Method. Photography as Self-awareness and Method of Learning}

\author{
María Isabel Soler Ruiz*
}

\begin{abstract}
Resumen: Esta investigación pretende sistematizar una estrategia pedagógica, un diseño heurístico de autoconocimiento que aúne el trinomio educación-arte-investigación. Se parte de metodologías propias implementadas en la asignatura de Fotografía de primer curso del Grado en Bellas Artes de la Universidad de Granada, España, donde se trabajan las bases del "Dan Tian" y conceptos del taoísmo difundidos por Mantak Chia. El artista-estudiante descubrirá ese lenguaje propio de la imagen que hace visible nuestro ser interno.
\end{abstract}

Palabras clave: Fotografía. Creación artística. Metodología. Taoísmo.

Abstract: The aim of this study is to methodise aspects of a pedagogical strategy, a heuristic design of self-awareness, that promotes the fusion of education, art and research. It is born out of methods developed by myself implemented during the module on photography as part of a Degree in Fine Arts at The University of Granada in Spain, using the foundations of 'Dan Tian' and concepts developed from Taoism by Mantak Chia. The student artist will discover their own way of expressing visual images which expose their inner being.

Keywords: Photography. Artistic Creation. Methodology. Taoism.

* Profesora Titular de Universidad. Facultad de Bellas Artes de la Universidad de Granada, España. isasoler@ugr.es 


\section{Introducción}

A menudo se le ha adjudicado a la fotografía los conceptos de "recuerdo", "memoria", "documento" o "registro", pero, ante todo, también es la construcción mental de una imagen que se materializa mediante el acto fotográfico.

El acto fotográfico se refleja en tres actitudes posibles: la primera, captar una imagen inesperada sin pensamiento previo; la segunda, buscar con una idea prefijada la imagen que se desea fotografiar; y la tercera, planear la escena y el relato que queremos representar. En los tres casos, de manera razonada o intuitiva, hay una recreación en el proceso creativo y una parte no controlada del mismo que hará que la imagen fotográfica final también revele el alma de su creador.

Cuando la fotografía ya está expuesta, el espectador quizás no sea consciente del diálogo constante que el artista-fotógrafo establece entre su mundo interior y el mundo exterior. El proceso fotográfico ofrece herramientas y conceptos para manifestar de manera consciente o inconsciente el yo creativo. En el camino hacia la imagen que hace visible lo invisible, la mente se libera de la rigidez que la ancla a las técnicas fotográficas para crear un nuevo lenguaje que exprese su ser interno. Cómo descubrir ese lenguaje propio es parte de una metodología artística que aplicaré a la metodología docente del arte.

El arte es objeto y sujeto de conocimiento que nos ayuda a entender nuestra mirada. Es, además, una herramienta de educación para una investigación natural del ser y su relación con el mundo. 
Así, el artista-docente es un traductor de lenguajes que facilita al artista-estudiante el contexto propicio para la auto-reflexión sobre sus procesos artísticos y le descubre el puente entre las distintas interpretaciones del mundo.

Esta investigación tiene como objetivo plantear unas pautas metodológicas para descubrir, por tanto, ese lenguaje propio que conduce hasta la imagen que hace visible lo invisible. Se parte de metodologías propias implementadas desde el curso 2015-2016 al 2018-2019 en la asignatura de Fotografía del primer curso del Grado en Bellas Artes de la Universidad de Granada (España) que trabajan las bases del "Dan Tian" y los conceptos extraídos del taoísmo difundidos por Mantak Chia (2016). Como propuesta se pretende sistematizar una estrategia pedagógica de diseño heurístico que posibilite fundir el trinomio educación-arte-investigación para concebirlo como una forma de vida que no escinda los componentes de nuestro ser interno: mente-corazón-cuerpo.

\section{Acto fotográfico, acto de conciencia}

Como artistas proyectamos en lo que construimos la esencia del ser mediante lenguajes diferentes. Como artistas-docentes, no basta con explicar cada lenguaje artístico mediante imágenes y palabras, sino que es necesario plantear la práctica artística para su reflexión y debate. Podría decirse que el estudiante de Bellas Artes es, a la vez, artista y espectador de su propia obra ya que al defenderla de forma consciente ante compañeros y compañeras, toma también el rol del docente. No hablaré entonces de una pedagogía sino de una 
heutagogía tal y como la definían los autores que la acuñaron, Hase y Kenyon, en el año 2000 (YTURRALDE, 2020) que consideran al estudiante como un adulto que se autoeduca y determina su propio proceso de aprendizaje. El docente debe desaparecer, hacerse invisible (OIDA, 2016) después de plantearles propuestas, acontecimientos y planteamientos que les sirvan como guía hacia la autoconciencia.

Tanto en los procesos creativos como en los resultados se proyecta el "self" o "sí mismo" que C.G. Jung y su equipo estudian en El hombre y sus símbolos (JUNG, 1997) y que desarrolla a lo largo de su carrera como psicólogo y como ensayista. Ya él utilizaba en sus consultas el dibujo como medio para que sus pacientes expresaran sus sueños (MORALES, 2020). De igual manera, proporciono herramientas al estudiante, que ya considero artista adulto, para "leerse", interpretarse y conocerse a través de su creación artística. Así, y desde mi experiencia creativa, propongo dos tipos de prácticas básicas al artista-estudiante: la creación individual en la que se enfrenta a sus procesos internos y la exposición de lo construido ante los demás. Docentes y estudiantes se convierten en investigadores de su propio proceso creativo hasta lograr "ver y verse" con el ojo del espíritu (MERLEAU-PONTY, 1964).

La fotografía será la herramienta vital para la autoexploración y el desarrollo de la conciencia del "sí mismo", pues el producto obtenido o imagen resultante es la proyección del ser interno del artista ante una mirada externa, que captará o interpretará el mensaje desde su propio contexto. El lenguaje fotográfico, como cualquier otro lenguaje, expresa el diálogo constante entre su mundo interior y su mundo exterior, una lucha contra la ceguera que puede llegar a ser visionaria cuando cesa la lucha. 
No obstante, hay aspectos engañosos en la fotografía que obstaculizan esa visión, pues la imagen, al ser captada a través de una cámara, parece surgir de algo externo a nosotros que interpretamos como subjetividad y que, en su origen, se asociaba a la idea de archivo de nuestra memoria histórica y personal. Sin embargo, la selección de la imagen fotografiada es siempre subjetiva y materializa percepciones o sensaciones de quien las elige para evocar emociones o reflexiones en quien las contempla.

En La mano que piensa, Pallasmaa (2018) destaca la inevitable relación del cuerpo con aquello que se crea. La mano sería la intermediaria. El gesto, en el dibujo previo a cualquier construcción escultórica, pictórica o arquitectónica, es una expresión corporal. El sujeto-fotógrafo, igualmente, necesita su gesto, su enfoque, su movimiento. Y lo necesita antes, durante y después de activar el obturador. La primera imagen ("imago" del latín y "eikon" del griego) nace en nuestra mente o cuerpo mental, activa nuestro cuerpo emocional y se materializa desde nuestro cuerpo al elemento físico. Por tanto, la fotografía es una estructura mental que genera una imagen, antes de ser captada por la cámara, para después hacerla visible ante los demás. Según Serge Tisseron (2000, p. 49) este proceso implica "dos series de operaciones psíquicas a la vez contradictorias y complementarias, de corte-captura por un lado y de abertura-conexión por otro", operaciones que adaptaré al diseño del método heurístico en tres fases: tras una exploración, se selecciona para luego producir el resultado a mostrar mediante exposición o publicación. Es un sistema de autoaprendizaje donde la docencia se inicia con una serie de ejercicios de entrenamiento o propuestas que motiven la experiencia en la práctica artística. 
Cuando Henry Cartier-Bresson nos habla del "instante decisivo" está considerando el momento del disparo fotográfico como el centro del acto fotográfico: "La fotografía es, para mí, el impulso espontáneo de una atención visual perpetua, que atrapa el instante y su eternidad" (CARTIER-BRESSON, 2003, p. 35). Tal y como él lo definía cuando recomendaba la lectura del libro El Zen en el tiro con arco (HERRIGEL, 2012), es el momento exacto en el que el arquero dispara la flecha sin aún salir del arco. Consciente o no, en ese momento lo importante para el artista-fotógrafo no es el resultado sino la conexión de las fuerzas internas, situadas en un centro energético de su cuerpo, con aquello que contempla. Esa conexión se establece en un estado de "vacío", entendido desde los conceptos taoístas "wu" y "xu", definidos como "el no haber" y "la nada" (CHENG, 1993, p. 78).

Para llegar a ese estado es necesario un equilibrio entre mente, corazón y cuerpo, tríada asociada con "los tres tesoros" o "Dan Tian", definidos más adelante, y con diferentes conceptos taoístas (Fig.1) promulgados por Mantak Chia (2016). No es fácil llegar a ese punto de conexión y equilibrio, pues actuamos utilizando un intelecto centrado en la técnica y en el relato razonado, y no desde un corazón unido a cuerpo y mente. El relato que surge de la razón, y piensa en el resultado como un premio, bloquea la fluidez creativa. 
Fig. 1 - Mapa conceptual de interrelación basados en los fundamentos ontológicos del taoísmo.

\begin{tabular}{|c|c|c|}
\hline MENTE & CORAZÓN & CUERPO \\
\hline atención & enfogue & intención \\
\hline energiza & dirige & transforma \\
\hline espirititu & alma & fuente \\
\hline estimull & intuición & accióz \\
\hline arco-flechas & diana & Rostura \\
\hline DAN TIEN SUPERIOR & DAN TIEN MEDIO & DAN TIEN INFERIOR \\
\hline
\end{tabular}

Fuente: Elaboración propia en base a Mantak Chia (2016)

Hay ocasiones en las que la propia fluidez y conexión con lo que se va a fotografiar consigue que el resultado se olvide y prevalezca el ser universal. En la película dirigida por Ben Stiller, La vida secreta de Warren Mitty, el fotógrafo interpretado por Sean Penn, persigue durante años fotografiar al tigre de las nieves y, cuando al fin lo consigue, lo contempla en la distancia desde su lente fotográfica para disfrutar el momento y llevarlo con él sin disparar. El fotógrafo desaparece, queda su ser esencial. (LA VIDA..., 2013).

Esta propuesta aspira, en la educación universitaria, a un "idealismo mágico" que abogue por una metodología útil, aplicable tanto al profesorado como al estudiante, que desarrolle el autoaprendizaje mediante la creación artística (Fig.2). Una metodología que dialogue sobre las problemáticas específicas de un grupo formado por estudiantes y docente/s en un espacio de encuentro cultural que derive en la gestión e investigación del arte, no sólo como objeto de conocimiento sino también como sujeto de conocimiento. El objetivo utópico es la disolución del rol de docente y de estudiante como tal para llegar al ser más genuino. 
Fig. 2 - Mapa conceptual de idealismo mágico.

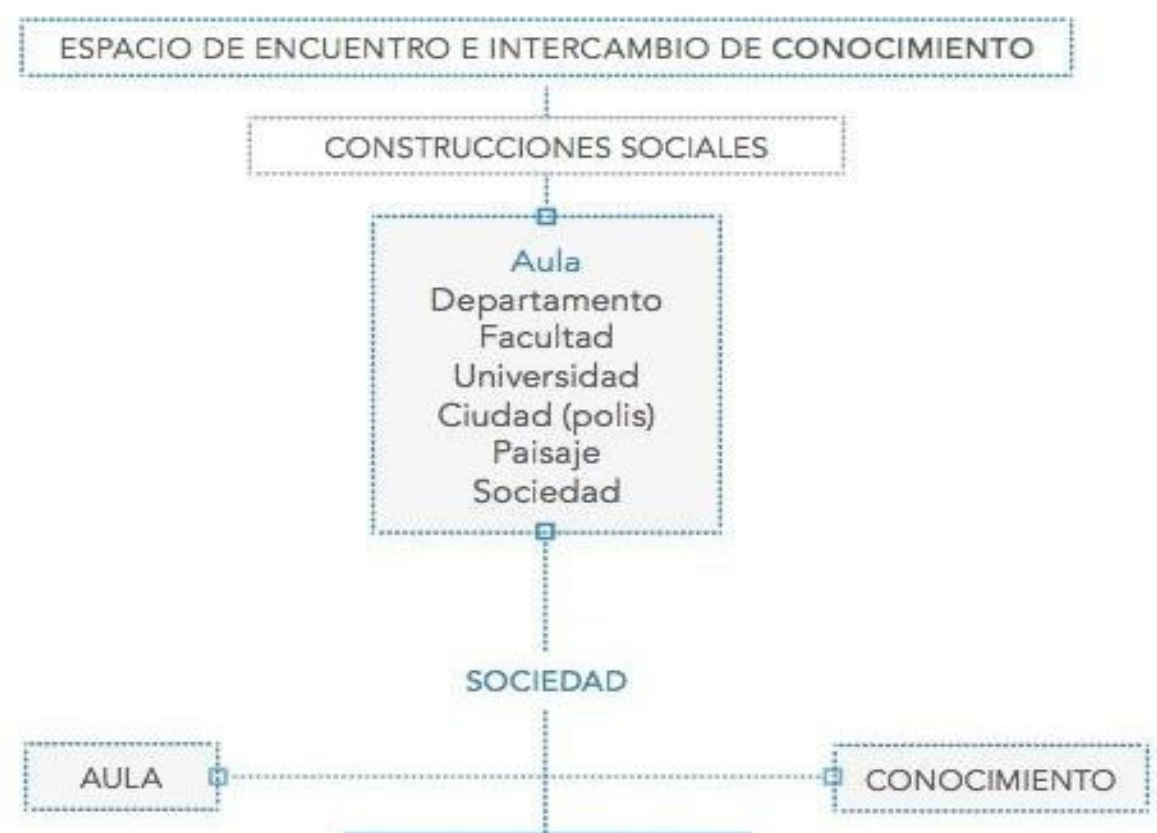

IDEALISMO MÁGICO

ESPACIO POLITICO DE GESTIOON E INVESTIGACION SOBRE EL CONOCIMIENTO

Fuente: Elaboración propia

\section{Método Sherezade. Docente invisible, artista visible}

“[...] Tenemos tres niveles de actividad y conciencia: nuestro cuerpo físico en el espacio, nuestra relación con los demás y el observador silencioso". (OIDA, 2016, p. 136).

La docencia de la investigación en arte no es sólo una transmisión de conocimientos, sino una traducción de los lenguajes y de las experiencias en los procesos creativos. El puente entre los distintos lenguajes que esta propuesta plantea se establece mediante la palabra y la imagen, y el recurso básico que utilizo para un proceso de aprendizaje-enseñanza del arte es la acción artística.

Tras años de investigación en la práctica heutatogógica del 
arte y en la docencia de la asignatura de Fotografía, he llegado a las mismas conclusiones que María Acaso y Clara Megías (2016), esto es, que los sistemas tradicionales de enseñanza han sido erróneos en el desarrollo artístico de la creatividad y han fomentado las problemáticas de exclusión y fragmentación social por las siguientes razones: a.) Exceso de fragmentación de asignaturas en distintos niveles educativos; b.) El concepto de creatividad como un don; c.) División entre teoría y práctica, con sistema de conferencias como clases teóricas repetidas cada año y talleres como clases prácticas; d.) La exaltación de maestros o artistas clásicos en las clasesconferencias con "macrorrelatos" que se alejan de problemáticas actuales del alumnado; e.) Fomento del concepto taller como algo cerrado para la creación de objetos para su consumo.

La fragmentación que nos escinde tanto a nivel social como a nivel creativo procede de esa educación adversa, es por ello que dividimos en nuestra actuaciones cotidianas el intelecto del corazón y del cuerpo. Se promueve el intelecto olvidando las emociones o la expresión corporal y nos convertimos en mentes mecanizadas, de pensamientos rígidos e inflexibles. No hay forma de luchar contra eso a mano armada, pero sí de aportar recursos o estrategias para observar como testigos un cambio de conciencia.

María Acaso y Clara Megías (2016) aportan no sólo recursos sino un vocabulario adaptado al alumnado actual para explicarlos como aprender emulando ${ }^{1}$; educar como un remix realizado por un DJ"; charlas con microrrelatos de artistas vivos; creación de

1 María Acaso y Clara Megías hablan de "copiar", pero ese concepto no lo concibo, pues siempre hay una interpretación personal y un homenaje hacia quien se elige como modelo de Maestro. 
situaciones complejas en vez de objetos de consumo; contemplar la figura del "prosumidor" (productor + consumidor) en vez de la del "consumidor" o variar el "material mudo" por otras herramientas de discurso. Sin embargo, aunque comulgo con su filosofía y las ideas prácticas que exponen ambas, en sus propuestas plantean el rol del docente como director de un proyecto prefijado donde los estudiantes son los actores, mientras que en la propuesta que aquí se plantea la finalidad es que, tras esos anteproyectos o ejercicios de entrenamiento, el docente desaparezca para que sean ellos los que diseñen la escena final. Serán directores, actores, artistas, tramoyistas, diseñadores, periodistas, cámaras, ayudantes de cámara... cada cual asumirá su rol'2.

Propongo cada propuesta o ejercicio como acontecimientos inesperados para construir conciencia (ARAÑÓ, 2005) o entornos de problemas (DE LAIGLESIA GONZÁLES DE PEREDO, 2008) que activen la percepción del centro creativo (ARNHEIM, 1998), pero no hay una adquisición por transmisión de conocimientos sino re-conocimiento de aquello de lo que cada miembro que "habita" el aula es consciente (insisto, estudiante o docente). El aula se convierte entonces en un espacio de reflexión, de gestión y de investigación, un espacio político (DEL RÍO, 2008) donde el grupo conforma una microsociedad, un reflejo del contexto social, cultural, personal que habitamos.

Al generar un ambiente de investigación grupal nos

2 Como ejemplo comparto los resultados del ejercicio de entrenamiento de la primera semana de la asignatura de Fotografía de $1^{\circ}$ curso del Grado en Bellas Artes del año académico 2018-2019. El montaje fue realizado por Carmen Ruiz de Almirón y la fotografía a cargo de Araceli Vico. Exposición Identidades, recuperado el día 20 de octubre de 2020, de: https://bit.ly/3quGqfO 
concentramos en nuestro proceso y al marcar previamente unos tiempos de resolución descubrimos cuáles son nuestros límites y nuestro territorio natural de exploración, pues "la grandeza de un artista surge a partir de la identificación de su propio territorio y de sus límites personales más que de un deseo indeterminado de libertad." (PALLASMAA, 2018, p. 126). En ese camino de exploración de sus propios territorios, de selección y reconocimiento de sus límites, de acción creativa y producción reflexiva surgen conflictos de todo tipo que exigen la autoobservación para solucionarlos, pues "equilibrar el movimiento interior con la actividad exterior es una tarea muy delicada" (OIDA, 2016, p. 75).

El conjunto de ejercicios o herramientas de entrenamiento enlazados que conforman el proceso metodológico sirven de guía al estudiante y al docente para observar nuestros niveles de percepción. A la hora de diseñar el método heurístico, que he denominado "método Sherezade", recurro a las tres vertientes que han alimentado mi creatividad en los proyectos artísticos: la vertiente poética-literaria; la vertiente de expresión fotográfica en instalación y la vertiente de entrenamiento cuerpo-naturaleza como aprendizaje vital. En ellos la palabra es la inspiradora de la imagen y la imagen la inspiradora de la palabra y viceversa (Fig. 10).

Aunque en determinados momentos cada vertiente (poética, fotográfica, corporal) pueda escindirse, las tres necesitan de un largo proceso ritual hasta convertirse en un proyecto artístico $\mathrm{y}$, en cualquiera de las tres vertientes, es difícil alinear la mente, el corazón y el cuerpo. En aparente contradicción, la palabra se suele asociar al pensamiento lógico y el acto creativo al corazón, pero cuando la palabra es parte de un ejercicio creativo el flujo va igualmente de la 
mente al corazón y viceversa, y siempre con el uso del cuerpo como intermediario. Fortalecer las emociones tanto como el intelecto y el cuerpo es fundamental a la hora de crear y proyectarte en lo que construyes.

En la práctica de las artes marciales y en las prácticas taoístas, como el Chi Kung", se entrena el desarrollo de los tres "Dan Tian", "campo del elixir" o "los tres tesoros", desde tres zonas de nuestro cuerpo: el "Dan Tian" superior entre las cejas (mente), el Dan Tian medio (corazón) en el plexo solar y el "Dan Tian" inferior (cuerpo) bajo el ombligo (CHIA, 2016) que no pueden escindirse, pero sí movilizar la energía de uno a otro para llegar al concepto de "vacío" que nos definía François Cheng (1993) como un estado de silencio. Durante estas prácticas he entendido que lo fundamental es el desarrollo y la concentración en el centro energético inferior, también llamado "Hara" en las artes marciales japonesas (ENDO, 2019). Cada "Dan Tian" lo asocio a otros conceptos de referencia (Fig. 1). Podemos partir de cualquiera de ellos para llegar a los otros dos en pro de un equilibrio creativo que permita abordar la actividad creadora como generadora de experiencias. Cada acción artística diseñada se orienta hacia la conexión de lo corporal con el espacio y con las personas que lo ocupan; la fotografía, con la cámara fotográfica o el móvil como herramientas de trabajo, es la excusa.

En las propuestas metodológicas comenzamos por la experiencia más emotiva y relacional (corazón), continuamos por el estudio de fotógrafos y fotógrafas que generan debates intelectuales

3 El conocimiento del Chi Kung es básico en el estudio de la Medicina Tradicional China o MTC. 
(mente) y, finalmente, con el trabajo de campo y la acción final (cuerpo). Aunque distingo cada parte como parte de un proceso que unifica las tres, es en la última propuesta donde llegan a su acto creativo. En el proyecto final el docente desaparece, los estudiantes trabajan libremente, son sus propios guías para llegar al "momento blanco" (CAMERON, 2019), momento de inspiración o momento intuitivo de creación (ARNHEIM, 1998), el punto exacto que comentábamos en el tiro con arco (HERRIGEL, 2012) para crear desde el silencio (Fig. 3).

Fig. 3 - Mapa guía de los bloques del diseño heurístico planteado en la asignatura de Fotografía del Grado en Bellas Artes de la Universidad de Granada. 2015-2019

\begin{tabular}{|l|l|l|}
\hline CORAZÓN & EXPLORACIÓN. Investigación & $\begin{array}{l}\text { La expansión de los límites de la imagen artística } \\
\text { en los rituales cotidianos. }\end{array}$ \\
\hline MENTE & SELECCIÓN. Edición & $\begin{array}{l}\text { Aspectos formales y discursivos que identifican } \\
\text { al sujeto y ejemplifican conceptos fotográficos. }\end{array}$ \\
\hline CUERPO & ACCIÓN. Producción & $\begin{array}{l}\text { Ritos y estrategias de acción desde las mitologías } \\
\text { personales. }\end{array}$ \\
\hline
\end{tabular}

Fuente: Elaboración propia

\section{Resultados}

El diseño heurístico que describo a continuación, se desarrolló en los cursos 2015-2019 en la asignatura de Fotografía ( 6 créditos) de $1^{\circ}$ curso (grupos R, Y y Z) del Grado en Bellas Artes impartida en la Facultad de Bellas Artes de la Universidad de Granada (1er semestre) y se resume en tres bloques que se retroalimentan entre sí y que fusionan temas de los contenidos de diversas asignaturas del este grado. A partir de ellos describo los ejercicios de entrenamiento que se superponen en el tiempo. 
En la primera propuesta, Exploración/Investigación (Fig. 4), los objetivos son: a.) reconocer la presencia del otro, es decir, trabajar sobre el concepto de respeto a la alteridad; b.) traducir lenguajes desde la palabra oral y escrita a la imagen y viceversa; c.) concentrar la atención desde el individuo hacia la conexión entre sujetos y hacia la conexión con el espacio; d.) concienciar sobre el trabajo en equipo; e.) buscar soluciones a posibles conflictos individuales o grupales. Para ellos, los artistas de referentes fueron: Paul Auster, Sophie Calle, Luis González Palma, Isabel Muñoz, Eduardo Momeñe, entre otros.

Durante la primera parte (4 horas), predomina el trabajo sobre el aspecto emocional o del "corazón", cada estudiante presenta a un compañero o compañera y lo define al resto del grupo con una palabra y con una imagen que represente ese concepto. La imprimen en papel desde móvil o cámara y exponen al aire libre a modo de instalación o intervención. En la exposición cada persona toma un rol: diseño de cartelería, nota de prensa, periodista, etc.

En la segunda parte ( 8 horas), la parte emocional contacta con la parte intelectual o de la "mente", y se lleva a cabo un debate de resultados donde cada alumno o alumna añade una palabra a cada imagen. Posteriormente, crean un texto libre a partir de las palabras recibidas en su imagen fotográfica. Finalmente, se lleva a cabo la maquetación de un catálogo impreso de la exposición con los textos y las imágenes.

En la tercera parte (4 horas), se acentúa la acción o aspecto "corporal" desde lo intuitivo y se procede a fotografiar imágenes que dibujen cada letra de la palabra que definió a cada estudiante en espacios como la facultad o en recorridos por la ciudad. Finalmente, 
se unen para formar la palabra, intervenir el espacio y establecer debates.

Fig. 4 - Propuesta 1. Exploración/Investigación.

Extracto del catálogo de exposición "Identidades".

Asignatura: Fotografía (Grupo R).

Facultad de Bellas Artes, Universidad de Granada. 2018.
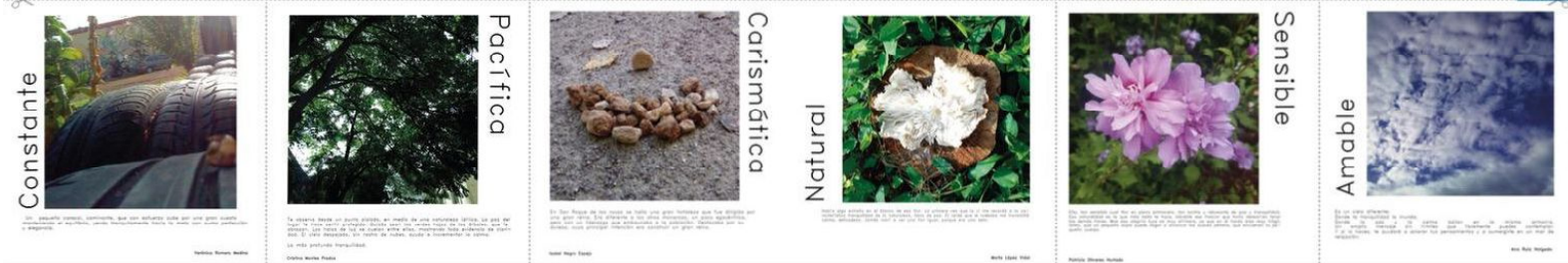

Fuente: Archivo de la autora

En la segunda propuesta, Selección /Edición (Fig. 5), los objetivos que se plantean son: a.) experimentar con las herramientas y procedimientos fotográficos; b.) conocer las distintas técnicas de edición; c.) guiarse por la intuición y autoexplorar los límites; d.) explorar territorios fotográficos bajo la mirada de artistas que utilizaron la fotografía como una herramienta de autoconocimiento. Entre los artistas referentes para los debates se encuentran Kim Sooja, Marina Abramovic, Alfredo Jaar, Santiago Sierra, Walter Astrada, Nobuyoshi Araki, Harry Calhagan, Hiroshi Sugimoto y Jungjin Lee. Y en cuanto a los artistas referentes para edición y emulación de técnicas: Susy Gómez, Vik Muniz, Georges Rousse, Ouka Leele, Mister G., Ilan Wolf, Sam Taylor-Wood, Alberto Ros, Noboyuki Kobayashi, Walter Astrada, Daido Moriyama, Isabel Muñoz, Fernando Manso y Sebastiao Salgado.

En esta propuesta, durante la primera parte ( 8 horas) se lleva a cabo la visita a la biblioteca para seleccionar catálogos publicados y obras de fotógrafas. Se realiza la ficha técnica de análisis semántico 
y sintáctico para proceder a su exposición y debate.

Durante la segunda parte (14 horas) se lleva a cabo la selección de un espacio a fotografiar para un concurso ya publicado, así como el tipo de cámara (analógica o digital) y el revelado (químico o digital). Finalmente, se realiza una selección y edición de imágenes.

Fig. 5 - Propuesta 2. Selección/Edición. Extracto del catálogo de exposición "Fake News".

Asignatura: Fotografía (Grupo Z).

Facultad de Bellas Artes, Universidad de Granada. 2018.
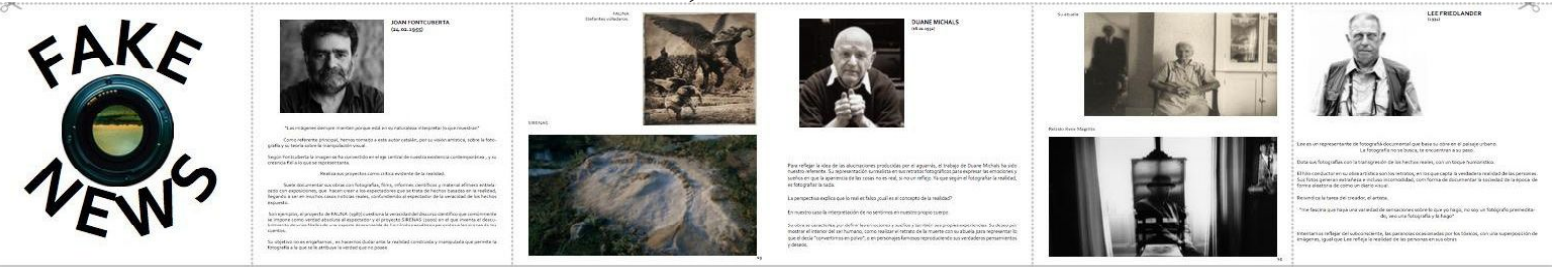

Fuente: Archivo de la autora

En la tercera propuesta que aquí se presenta, Acción/ Producción (Fig. 6), los objetivos que se plantean son: a.) revisar la historia de la fotografía como lenguaje interdisciplinar. b.) promover la creatividad genuina; c.) valorar y respetar la creación propia y la ajena; d.) apreciar el diálogo y el debate como formas de comunicación y solución a posibles conflictos. En este caso, entre los artistas referentes a nivel metodológico se encuentran: Joan Fontcuberta, Duane Michals, Ana Casas Broda, Francesca Woodman, Javier Valhonrat y Ernesto Bazán.

En este caso, durante la primera parte (14 horas) se aboga por la libertad de creación tanto si se trata de un proyecto individual o en grupo. Se plantean dos posibles opciones para motivar en la búsqueda de ideas. Por un lado, crear un álbum familiar ficticio donde haya cuatro generaciones de fotógrafos/as. En este sentido, 
pueden emular fotografías históricas. Y, en segundo lugar, crear un proyecto de intervención, instalación o acción performativa en el espacio que deseen. En la segunda parte (8 horas), se lleva a cabo el montaje de la exposición colectiva y la inauguración de la misma. Tras ello, se realiza una valoración de los resultados.

Fig. 6 - Propuesta 3. Acción/Producción. Prueba de exposición. Asignatura: Fotografía (Grupo Y).

Facultad de Bellas Artes, Universidad de Granada. 2018

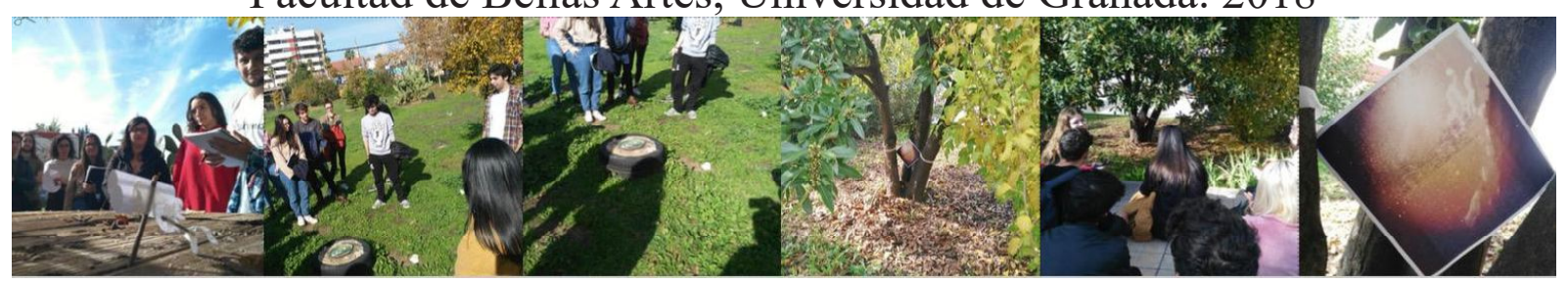

Fuente: Archivo de la autora

\section{Debate de los resultados}

"A medida que el proceso de individuación avanza, por paradójico que pueda parecer, la persona tiende a romper su coraza de ensimismamiento y se proyecta hacia el mundo. Huye del aislamiento, se hace ser-en-el-mundo". (MORALES, 2020, p. 252).

El objetivo primordial de este enfoque ha sido el de concebir el acto creativo como un acto ritual que equilibre mente, corazón y cuerpo: un acto o rito de paso que permita a quien lo realiza la transición de un estado de conciencia a otro o la variación de sus niveles perceptivos (VAN GENNEP, 2013). Cada una de estas propuestas se han planteado como acciones rituales que se centran en la observación del proceso creativo sin enjuiciamiento crítico. Cada acción es compartida y requiere un maestro-guía, una suma de 
individuos y un lugar de desarrollo y expansión de límites.

La búsqueda de soluciones a los problemas complejos que se plantean forma parte de la experiencia particular del proceso de creación de cada estudiante ante la docente como testigo. Tras los resultados de cada propuesta, el grupo y cada individuo (sea estudiante o docente) se hace consciente de cómo el proceso ha pasado por distintas fases que podemos equiparar con las de cualquier rito: fases de dispersión; enfrentamiento con uno mismo; miedos y consiguientes bloqueos; negación de lo aprendido; descolocación; caos (fases que interpreto como deconstrucción); destellos de soluciones creativas; identificación con "el otro"; recapitulación; aceptación; limpieza; muerte psicológica; y reconstrucción creativa, libre y singular que parte de un vacío, un silencio, entendido este como un estado o como fuente de lo absoluto.

En la etapa de exploración predomina la observación de uno mismo (actos cotidianos, cuerpo, contexto personal...) para aprender a expresar sus intereses a otro. En consecuencia, se mira al otro como espejo en un espacio de relación propicio al diálogo. Es un ejercicio de traducción, traducimos lo observado a una palabra concreta que inicie el diálogo con el otro y esta palabra se traduce en una imagen y esa imagen a un espacio o contexto. Predomina el Yo-Otro. Siempre partiendo de sus imágenes, se inician debates que toman derroteros no previstos de gran interés para observar la formas de autoexploración y completarlas con la comparación de las experiencias de artistas actuales reconocidos socialmente. Mediante estos ejercicios de reflexión, la palabra actúa como el resorte del proceso creativo que, en aparente contradicción, los libera del pensamiento inflexible. 
Durante el desarrollo de la segunda etapa de selección, comienzan a elegir intuitivamente su propios medios de expresión. A la hora del trabajo de campo, cuando seleccionan espacios o temas de investigación, comienza la búsqueda de un equilibrio entre lo interno y lo externo. Hay cierta confusión en la relación con las herramientas y el laboratorio, deben conocer reglas clásicas para romper con ellas. Predomina el Yo (Fig. 7). Se debate sobre los discursos de diferentes artistas que usan el lenguaje poético como recurso expresivo frente al lenguaje periodístico o documentalista, poesía vs prosa. Igualmente se analizan las tres actitudes del artista ante la cámara que lo conduce a un tipo de edición y producción diferente.

En primer lugar, la actitud del paseante sin fin aparente que dispara justo en el momento de una situación inesperada. $\mathrm{Su}$ única motivación es el acto fotográfico. Esto exige atención, concentración, estado de alerta ante lo externo, y una gran conexión con su centro interno, pues no hay una idea previa, ni un tema o estudio previo. Lo importante aquí es la búsqueda, la exploración y el proceso a posteriori de selección, de edición, de producción y de postproducción. Hay una importante conexión con el ser interno que ayuda en la búsqueda.

En segundo término, la actitud del investigador que con una razón previa y un tema busca la imagen deseada. En este caso el proceso de edición, producción y postproducción es importante. El proyecto exige un amplio estudio y conocimiento sobre el tema.

Y, por último, la actitud del científico que imagina, prepara y prevé la escena deseada y el motivo a fotografiar. El pre-proyecto cobra importancia a la hora de la toma fotográfica. La técnica correcta, su obsesión. Exige experimentación e, igualmente, una 
profunda concentración. Sin embargo, en los tres casos el proceso interno que el artista vive durante su acción creativa es el mismo.

Cada artista-estudiante va identificándose con alguna de estas actitudes para visualizar poco a poco de forma consciente su anteproyecto. En la propuesta final, cuando exponen su proyecto personal y se centran en la producción, ya hay un equilibrio entre mente-corazón-cuerpo desde la acción. A nivel de grupo deciden el contexto de intervención fotográfica para la exposición, deciden el espacio, la localización y el cronograma (fecha, duración y público) dentro de los márgenes que estipula la universidad. Durante el proceso investigan sobre los artistas que avalan su producción y lo exponen para su debate. En esta tercera etapa, orientada a un público, predomina la comparación con lo externo. El Yo debe estar equilibrado para no dejarse llevar por el Ego predominante que suele exigir la exposición pública del yo creativo ante la sociedad (Fig. 8).

\section{Conclusiones}

El paralelismo entre la creación artística y la docencia creativa permite al artista-docente llegar a una visión más holística de su realidad. Desde la investigación artística universitaria he podido vincular, en ocasiones y no sin dificultad, los tres aspectos mencionados (mente-corazón-cuerpo) que habitualmente escindimos.

El viaje, como trabajo de campo y exploración fotográfica, me ha llevado a estados de meditación propicios para el acto creativo, momentos de silencio y de vacío, pero también me ha conducido a 
fases de dispersión, inseguridad o negación de lo realizado. En otras situaciones, los procesos técnicos necesarios para que otras personas puedan visualizarlos, y descubrir aspectos nuevos para mí, a veces han bloqueado las decisiones o han interferido el flujo creativo. Son zonas de sombras que, indefectiblemente, van ligadas a la luz que las proyecta. La conciencia de estas sombras (Fig. 9) en negativo unidas a la luz del positivo, como en una suerte de Yin-Yang, permite el desbloqueo para un nuevo flujo de creatividad. Los recursos de mi investigación artística utilizados para ello son las herramientas que ofrezco al artista-estudiante. Artistas que he encontrado en su rol de estudiantes han confiado en ellas y me han devuelto con generosidad extrema sus conocimientos para mi propio aprendizaje. Como en los cuentos de Sherezade, nuestras historias quedan enlazadas.

Fig. 7 - C. Ruiz de Almidón Lanz. "Evolución del yo". Asignatura: Fotografía.

Facultad de Bellas Artes, Universidad de Granada. 2018

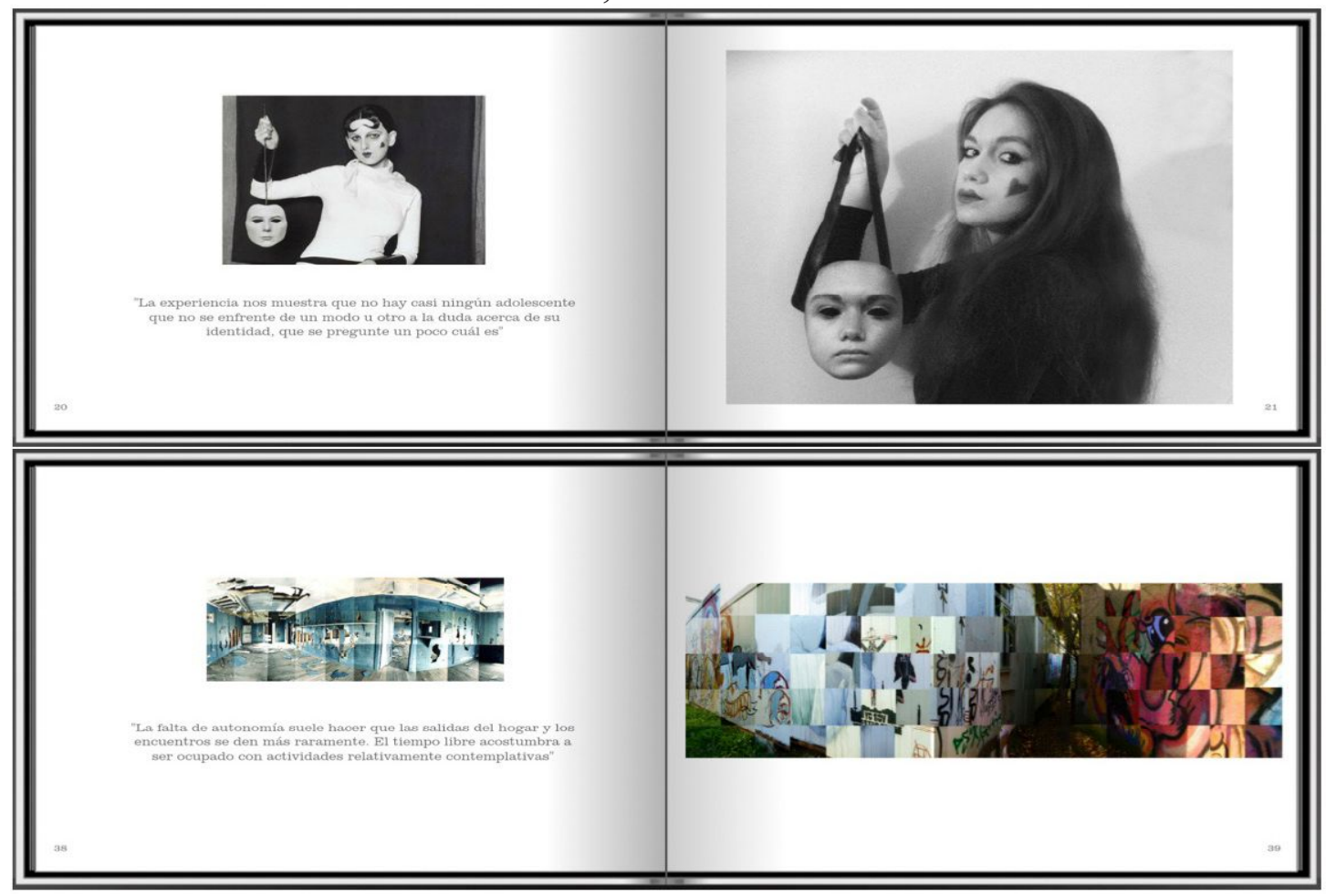

Fuente: Archivo de la autora 
Fig. 8 - L. Grande, C. Montes, C. Gómez, B. Rodríguez.

Ego, el asesino. Bitácora de un matador acomplejado. [Poesía: Lucía Grande].

Asignatura: Fotografía.

Facultad de Bellas Artes, Universidad de Granada, 2018

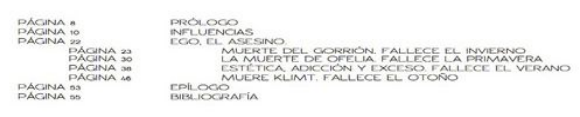

ÍNDICE

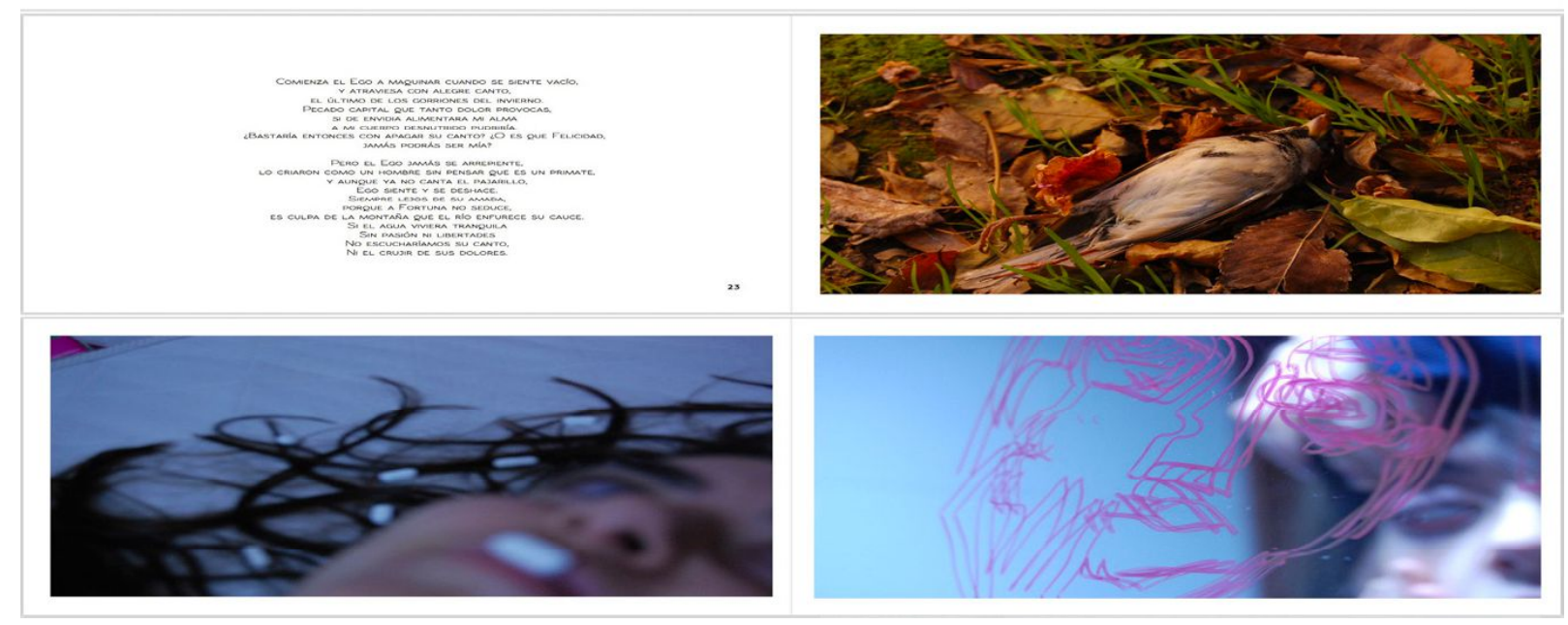

Fuente: Archivo de la autora

Fig. 9 - C. Rodríguez Bravo "Cárcel de cristal".

Asignatura: Fotografía.

Facultad de Bellas Artes, Universidad de Granada, 2018.
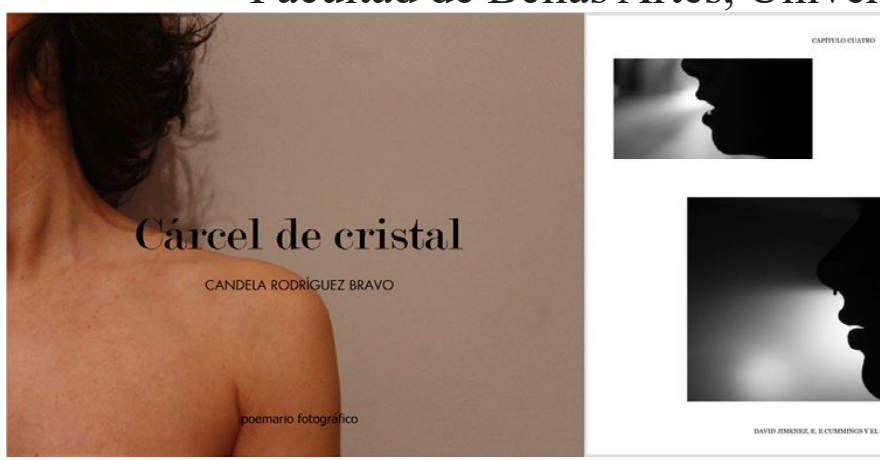

Renacimiento

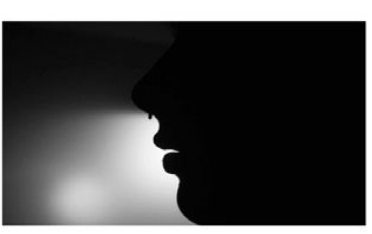

Hay una larga creencia,
en cómo se debe alcanzor

la felicidad que se ansia,

como principio fun
y razón de existir.

Muchos creen conocer la verdad;

pero solo algunos saben,

te conviertes en tu propio Dios.

Fuente: Archivo de la autora 
Fig. 10 - Evocaciones
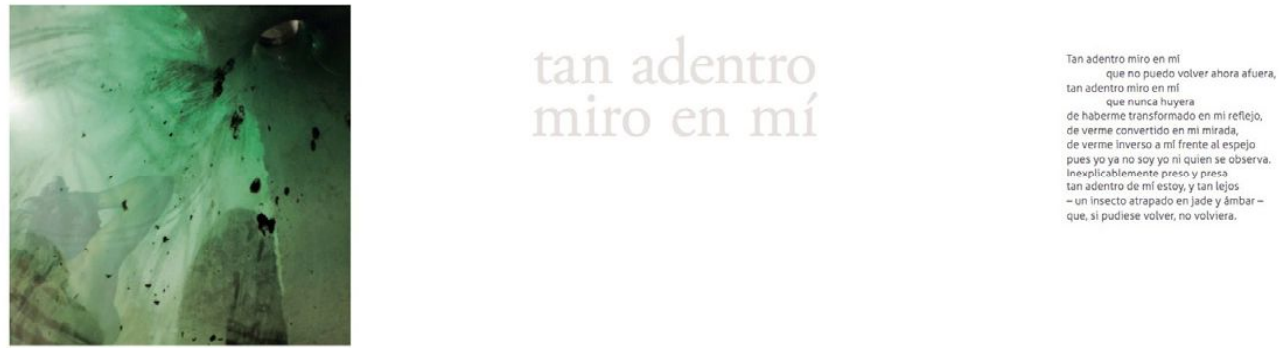

Fuente: María Isabel Soler Ruiz (2017, p. 17-19).

\section{Referencias}

ACASO, María; MEGÍAS, Clara. Art thinking. Cómo el arte puede transformar la educación. Barcelona: Paidós Educación, 2016.

ARAÑÓ GISBERT, Juan Carlos. Estructura del conocimiento artístico. En: Marín Viadel Ricardo (ed.). Investigación en educación artística. Granada: Universidad de Granada; Sevilla: Universidad de Sevilla, 2005. p. 19-42.

ARNHEIM, Rudolf. Hacia una psicología del arte. Arte y entropía. Madrid: Alianza, 1998.

CARTIER-BRESSON, Henri. Fotografiar del natural. Barcelona: Gustavo Gili, 2003.

CAMERON, Julia. El camino del artista. Madrid: Aguilar, 2019.

CHENG, François. Vacío y Plenitud. Madrid: Siruela, 1993.

CHIA, Mantak. Equilibrio energético a través del Tao. Madrid: Neo-Person, 2016. 
DE LAIGLESIA GONZÁLEZ DE PEREDO, Juan Fernando. Ideología institucional y carácter autorreflejo del arte. En: DE LAIGLESIA GONZÁLEZ DE PEREDO, Juan Fernando; RODRÍGUEZ CAEIRO, Martín; FUENTES CID, Sara (ed.). Notas para una investigación artística. Vigo: Universidad de Vigo, 2008. p.19-34.

DEL RÍO, Alfonso. En torno a la escultura: algunas consideraciones acerca de la enseñanza de la escultura. En: MAESO RU$\mathrm{BIO}$, Francisco (coord.). El arte de enseñar el arte. Metodología innovadora en Bellas Artes. Sevilla: Diferencia, 2008. p. 67-86. (Colección Arte y Educación).

ENDO, Seishiro. Vibración y conexión. El Aikido que yo busco. Barcelona: Alas, 2019.

GRANDE, Lucía; MONTES, Cristina; GÓMEZ, Cristina; RODRÍGUEZ, Blanca. Ego, el asesino. Bitácora de un matador acomplejado. Granada: Facultad de BBAA, Universidad de Granada, 2018. Não publicado. Archivo da autora.

HERRIGEL, Eugen. El Zen en el tiro con arco. Madrid: Gaia, 2012.

JUNG, Carl Gustav. El hombre y sus símbolos. Barcelona: Caralt, 1997.

LA VIDA secreta de Warren Mitty. Direction: Ben Stiller. Los Angeles, Califórnia, Estados Unidos: 20th Century Fox, 2013. 1 película (114 $\mathrm{min})$ color.

MERLEAU-PONTY, Maurice. L'oeil et l'esprit. Paris: Gallimard, 1964.

MORALES, Alberto. En el diván de Jung. Un encuentro terapéutico. Madrid: Manuscritos, 2020. 
OIDA, Yoshi. El actor invisible. Barcelona: Alba, 2016. (Colección Artes Escénicas).

PALLASMAA, Juhani. La mano que piensa. Sabiduría existencial y corporal en la arquitectura. Barcelona: Gustavo Gili, 2018.

RODRÍGUEZ BRAVO, Candela. Cárcel de cristal. Granada: Facultad de BBAA, Universidad de Granada, 2018. No prelo. Archivo da autora.

RUIZ DE ALMIDÓN LANZ, Carmen. Evolución del yo. Granada: Facultad de BBAA, Universidad de Granada, 2018. No prelo. Archivo da autora.

SOLER RUIZ, María Isabel. Evocaciones. Granada: Sonámbulos, 2017.

TISSERON, Serge. El misterio de la cámara lúcida. Fotografía e inconsciente. Salamanca: Universidad de Salamanca, 2000.

VAN GENNEP, Arnold. Los ritos de paso. Madrid: Alianza, 2013. YTURRALDE, Ernesto. Heutagogía: el aprendizaje auto-determinado. Disponible en: https://www.heutagogia.com/. Acceso en: 15 sep. 2020. 